\title{
ScIDoC
}

\author{
International Journal of Ophthalmology \& Eye Science (IJOES) \\ ISSN: 2332-290X
}

\section{Surgical Management Of Ectropion At Tilganga Institute Of Ophthalmology}

Research Article

\author{
Malita Amatya ${ }^{1 *}$, Rohit Saiju², Purnima Rajkarnikar Sthapit ${ }^{3}$, Ben Limbu ${ }^{4}$ \\ ${ }^{1}$ Principal Investigator Tilganga Institute of Ophthalmolgy, Oculoplastic Surgeon, Oculoplasty department, India. \\ ${ }^{2}$ Tilganga Institute of Ophthalmolgy, Oculoplastic Surgeon, Oculoplasty department. \\ ${ }^{3}$ Tilganga Institute of Ophthalmolgy, Oculoplastic Surgeon, Oculoplasty department. \\ ${ }^{4}$ Tilganga Institute of Ophthalmolgy, Oculoplastic Surgeon, Oculoplasty department.
}

\section{Abstract}

Purpose: To determine different types of surgical procedure and outcome done to treat ectropion.

Methods: Retrospective, observational study from Jan 2017 to Dec 2019 was performed on consecutive patients undergone ectropion correction surgery. Follow up was done on day-one, one-week, one-month, three-months, six-months and one-year postoperatively. Single or combined procedure done was noted. Anatomic and functional success was reported. Potential complications were recorded.

Results: Total 74 patients who fulfilled inclusion criteria, 45(60.81\%) male and 29(39.19\%) female, with the mean age of 59.82 \pm 21.82 (range 11 - 94). 42(56.76\%) had involutionalectropion, 14(18.92\%) Paralytic, 17(22.97\%) cicatricial and 1(1.35\%) had Mechanical ectropion. Single or combined procedure - Lateral tarsal strip, Medial spindle, LIS, Lazy-T, Wedge resection, Tarsorrhaphy, 3-Snip Punctoplasty, scar release with FTSG were done to correct ectropion. Anatomic success was found in $6(8.11 \%)$, functional success in $6(8.11 \%)$ and both success in $62(83.78 \%)$. Undercorrection was found on paralytic ectropion cases in $10(13.50 \%)$. Recurrence was found on $6(8.10 \%)$.

Conclusion: LTS was the most commonly done procedure. Single or combined procedure according to etiopathogenic cause gives good ectropion correction with patient satisfaction.

\section{Introduction}

Eyelid ectropion is an eyelid malposition in which the eyelid margin is turned outward from its normal apposition to the globe, thus resulting in tearing, exposure keratopathy, conjunctival hypertrophy and keratinization. Ectropion can be unilateral or bilateral and usually involves the lower eyelid. It is classified as congenital and acquired [1]. Congenitalectropion is a rare bilateral condition, caused by vertical deficiency of anterior lamella, may occur in isolation or may be associated with other conditions such as - Blepharophimosis syndrome, Buphthalmos etc. Acquired ectropion can be involutional, paralytic, cicatricial and mechanical $[2]$.

Involutional (atrophic) ectropion, also known as senile ectropion, occurs when the aging process results in atrophy of muscular and tendon structures, and the lid becomes abnormally lax and falls away from the orbit resulting from horizontal lid laxity of the medial and lateral canthal tendons, disinsertion of the lower lid retractors and orbicularis degeneration [3] and tissue relaxation followed by lid elongation, sagging, and conjunctival hypertrophy; usually involves lower eyelid [4].

Paralytic ectropion occurs as the result of ipsilateral facial nerve palsy and is associated with retraction of the upper and lower eyelids and brow ptosis as well as horizontal laxity resulting in lower eyelid ectropion or sag, lagophthalomos, and a significant risk of exposure keratopathy $[1,5,6]$.

Cicatricialectropion is due to shortening of anterior lamella formed by scarring due to ocular burns, trauma, or inflammation acts as the main retracting force on the lower lid $[1,4,7]$.

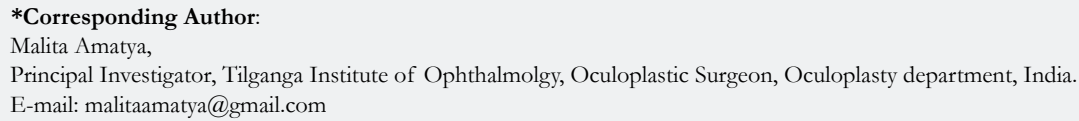

Citation: Malita Amatya, Rohit Saiju, Purnima Rajkarnikar Sthapit, Ben Limbu. Surgical Management Of Ectropion At Tilganga Institute Of Ophthalmology. Int J Ophthalmol Eye Res. 2021;09(02):456-461. doi: http://dx.doi.org/10.19070/2332-290X-2100092

Copyright: Malita Amatya 2020 . This is an open-access article distributed under the terms of the Creative Commons Attribution License, which permits unrestricted use, distribution and reproduction in any medium, provided the original author and source are credited. 
Tumors or cysts near the eyelid margin mechanically evert the eyelid, causing mechanical ectropion $[1,8]$.

Medical treatment with lubricants offer only temporary relief of symptoms, whatever the cause, the correction of ectropion requires a surgical approach as first-line therapy and remains the mainstay for permanent treatment $[9,10]$.

Many surgical procedures have been described for the management of ectropion and varying success rates have been reported. Because of the multifactorial nature of the disease, it requires the association of different surgical procedures. Correction of ectropion remains surgically challenging and no entirely satisfactory surgical technique has yet been reported as each of the surgical procedure has its own advantages and drawbacks. For these rea- sons, oculoplastic surgeons explore alternative procedures as the accepted standard for the correction of ectropion [3, 9, 10]. Due to lack of comparative studies, the best surgical technique remains controversial.

The aim of this study is to analyze the patients who under went surgery for ectropion to determine the demographics, types of surgeries, anatomic and functional improvement with different procedures done at Tilganga, to assess complications and recurrences if any.

\section{Materials and Methods}

This is a retrospective, observational study ofpatients diagnosed with Ectropion who under went ectropion correction surgery

Figure 1. Distribution of gender.

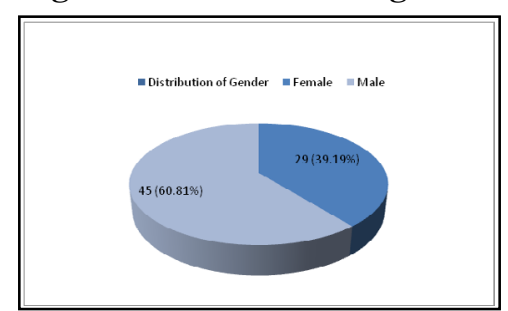

Figure 2. Distribution of involved ectropion eyes.

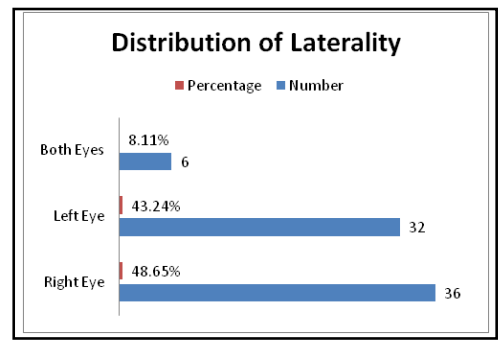

Figure 3. Distribution of types of Lower lid Ectropion.

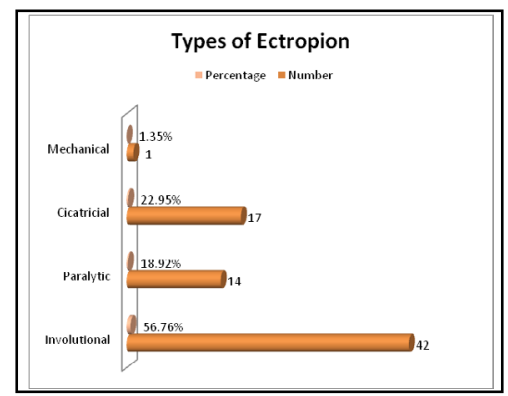

Figure 4. Distribution of clinical features.

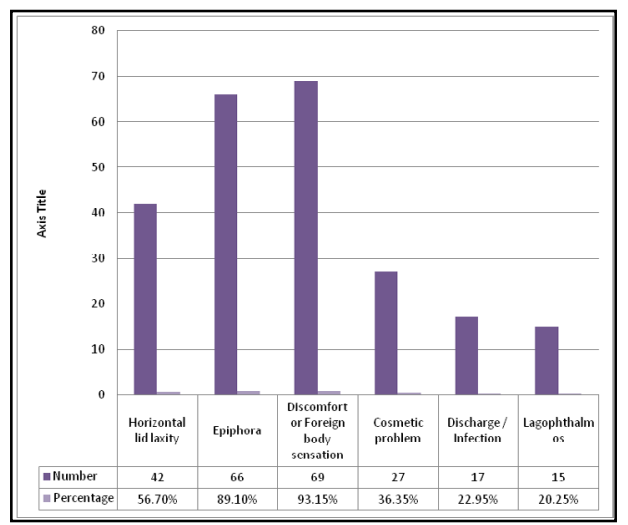


Figure 5. Showing the status of Lower lid punctum.

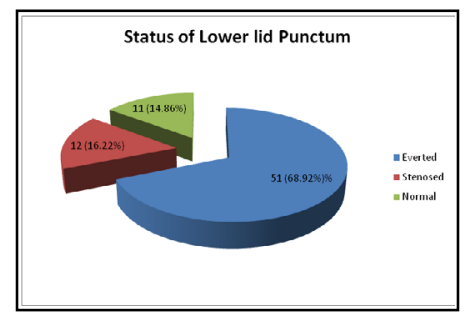

Figure 6. Clinically derived success after surgery.

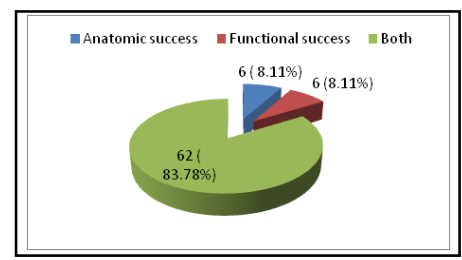

Table 1. Distribution of ectropion in male and female.

\begin{tabular}{|c|c|c|c|}
\hline Types of Ectropion & Total & Male & Female \\
\hline Involutional & $42(56.7 \%)$ & $27(36.45 \%)$ & $15(20.25 \%)$ \\
\hline Paralytic & $14(18.9 \%)$ & $6(8.1 \%)$ & $8(10.8 \%)$ \\
\hline Cicatricial & $17(22.95 \%)$ & $12(16.2 \%)$ & $5(6.75 \%)$ \\
\hline Mechanical & $1(1.35 \%)$ & 0 & $1(1.35 \%)$ \\
\hline
\end{tabular}

from January 2017 to December 2019 at Oculoplasty department of Tilganga Institute of Ophthalmology. We included all the diagnosed ectropion cases who underwent surgery and completed all postoperative follow ups at least 3 months and excluded those who underwent lid surgery in past, those who fail to come for follow up at least 3 months. Performa was designed and all the data were filled in MS excel sheets which includes - patients age, sex, laterality of eyes which underwent surgery, preoperative symptoms like: horizontal lid laxity, epiphora, discomfort or foreign body sensation, cosmetic problems, discharge/infection were recorded. Status of lower lid punctum (everted or stenosed or normal) recorded. Type of ectropion, which surgical procedure done, anatomic and functional success were noted. Any kind of complications after surgery, recurrences of ectropion if any were recorded.

Clinically derived functional success is defined by improved in symptoms and aesthetic appearance of the lids with respect to erythema and inflammation, and reduction in patients symptoms watering and irritation [3]. Anatomical success is defined as punctual position in the tear lake, facing inwards or occasionally slightly upwards [3]. All the patients were followed up on day one, one week, one month, three months, six months and one year. Those who completed follow up of at least 3 months were included in this study. Different surgical procedures used to treat ectropion were - LTS, MS, Lid inverting suture, Tarsorrhaphy, Scar release with Full thickness skin grafts, Wedge resection, Lazy-T procedure.

Data were collected with the help of a standard Performa designed for this study. All the data were entered in MS Excel. Codes decodes were done in MS Excel. Data were presented in table, pie chart and bar diagram. For qualitative data, number and percentage were calculated and for numerical data mean (SD) were calcu- lated. All the statistical analysis was done in SPSS 20.

\section{Results}

A total of 74 patients 80 eyes who fulfilled all the criterias and follow ups included 45(60.81\%) male and 29(39.19\%) female (Fig.1). There were 36(48.65\%) right eye, 32(43.24\%) left eye and $6(8.11 \%$ ) both eyes (Fig. 2 ) were operated for ectropion correction. The mean age was 59.82 with standard deviation 21.82 (range 11 - 94).

42(56.76\%) had involutionalectropion, 14(18.92\%) Paralytic, $17(22.97 \%)$ cicatricial and $1(1.35 \%)$ had Mechanical ectropion(Fig.3) (table1). All the patients of paralytic ectropion suffered from facial palsy. All the cicatricialectropion had history of trauma in past and one patient had burnt injury during childhood.

The most common clinical feature was discomfort or foreign body sensation in 69(93.15\%) followed by epiphora 66(89.10\%) (Fig.4). 51 patients presented with everted lower punctum, 12 with stenosed and 11 had normal lower punctum( Fig.5). 18(24.32\%) eyes had undergone LTS + Medial spindle, 14(18.90\%) eyes were corrected with LTS procedure only. There were single and combined procedures done to correct lower lid ectropion shown in table $2 \& 3$. This study found anatomic success on $6(8.11 \%)$, functional success on $6(8.11 \%)$ and both on $62(83.78 \%)$ cases Fig. 6.

One mechanical ectropion was due to basal cell carcinoma which was managed by wide excision mass and repaired with full thickness skin graft. All cases who received full thickness skin graft was harvested from postauricular area.

All the patients were symptomatically better postoperatively. 64 
Table 2. Different types of surgery done for Ectropion correction.

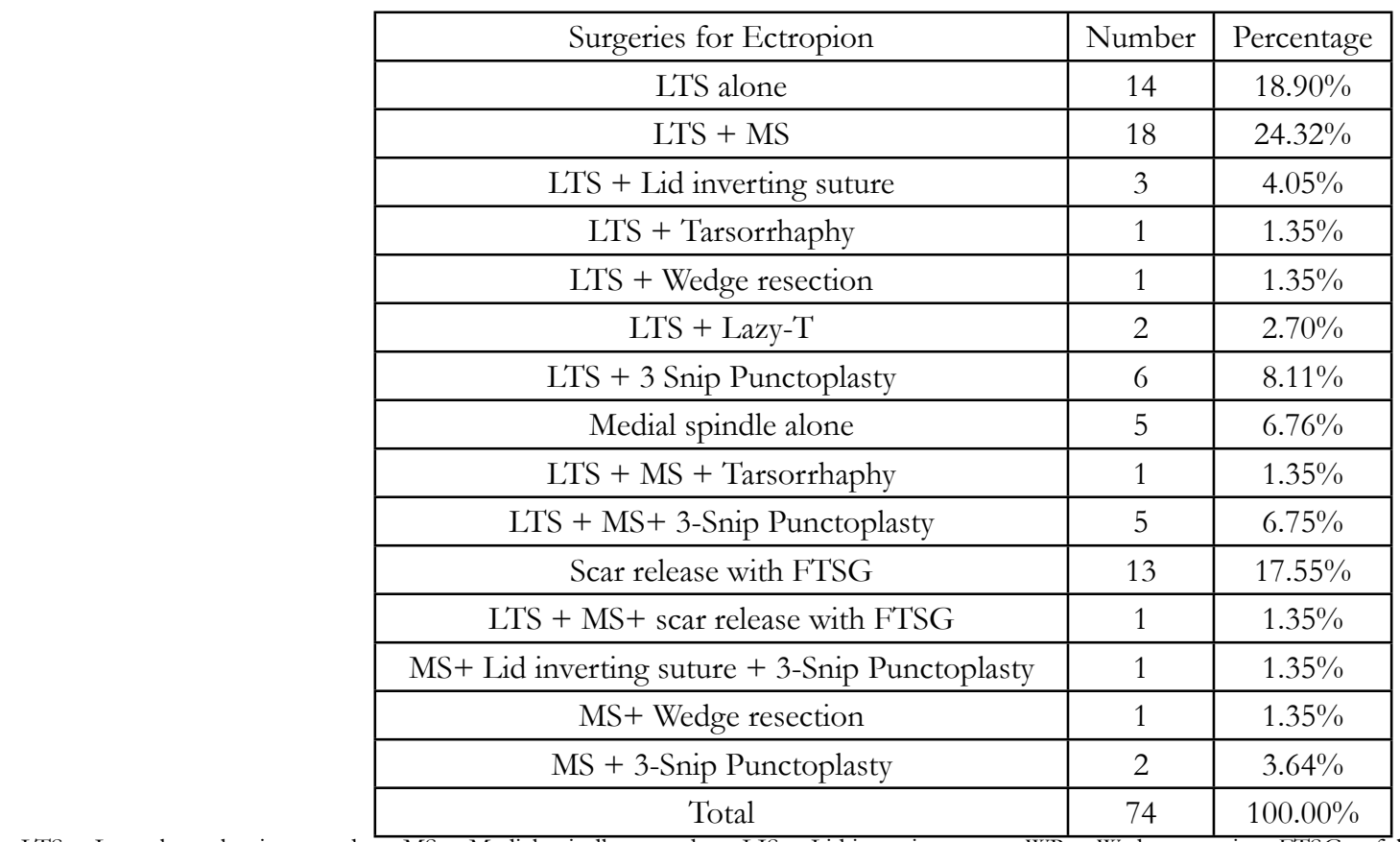

LTS $=$ Lateral tarsal strip procedure, MS $=$ Medial spindle procedure, LIS $=$ Lid inverting suture, WR $=$ Wedge resection, FTSG $=$ full thickness skin graft, OU $=$ both eyes.

Table 3. Showing the surgical procedures.

\begin{tabular}{|c|c|c|c|}
\hline $\begin{array}{c}\text { Involutional } 42 \mathrm{pt} \\
5 \mathrm{OU}\end{array}$ & $\begin{array}{c}\text { Paralytic } 14 \mathrm{pt} \\
1 \mathrm{OU}\end{array}$ & $\begin{array}{c}\text { Cicatricial } \\
17 \mathrm{pt}\end{array}$ & $\begin{array}{c}\text { Mechanical } \\
1 \mathrm{pt}\end{array}$ \\
\hline LTS 35 & LTS 13 & LTS 4 & $\begin{array}{c}\text { Excision of mass and full thickness } \\
\text { skin graft }\end{array}$ \\
\hline MS 23 & MS 7 & MS 4 & \\
\hline 3-Snip 13 & 3-Snip 1 & & \\
\hline Lazy-T 2 & LIS 1 & LIS 1 & \\
\hline WS 1 & Tarsorrhaphy 2 & $\begin{array}{l}\text { Scar release with full thickness } \\
\text { skin graft } 13\end{array}$ & \\
\hline LIS 1 & & & \\
\hline
\end{tabular}

Table 4. Complications observed after surgery.

\begin{tabular}{|c|c|c|}
\hline Complications & Number & Percentage \\
\hline Undercorrection & 10 & $13.50 \%$ \\
\hline Recurrences & 6 & $8.10 \%$ \\
\hline $\begin{array}{c}\text { Wound dehiscence / } \\
\text { infection }\end{array}$ & 3 & $4.05 \%$ \\
\hline Conjunctivitis & 1 & $1.35 \%$ \\
\hline Conjunctival Chemosis & 2 & $2.70 \%$ \\
\hline
\end{tabular}

patients had fully corrected. Under correction were seen in 10 patients who were paralytic ectropion, had residual lagophthalmos postoperatively. Their symptoms were significantly reduced and patients were comfortable even with undercorrection during all the follow ups. 6 patients had recurrence which was shown in table $4 \& 5$ and the surgery was done again when patient desired. Patients with wound infection and conjunctivitis were managed with use of topical antibiotics for 2 to 4 weeks duration.

\section{Discussion}

Different surgical techniques have been described to correct the lower lid ectropion as it has multiple etiopathological cause and varying success rates have been reported. In our study in total of 74 patients male predominance was $45(60.81 \%)$ and female $29(39.19 \%)$. The study by Mitchell et.al also found the male pre- 
Table 5. Showing the recurrences after surgery.

\begin{tabular}{|c|c|c|}
\hline Types of Ectropion & No. of patients & Month of recurrence \\
\hline \multirow{3}{*}{ Paralytic } & 2 & 2.5 \\
\cline { 2 - 3 } & 1 & 1.5 \\
\cline { 2 - 3 } & 1 & 3.5 \\
\cline { 2 - 3 } & 1 & 4 \\
\hline Involutional & 1 & 3 \\
\hline Total & 6 & \\
\hline
\end{tabular}

dominance of about $43.3 \%$.11In study by Damasceno et. $\mathrm{Al}$ [12] had ectropion prevalence of $7.7 \%$ males which was more than females $2.9 \%$. We found those with involutional ectropion were of all above 50 years of age. This result is not surprising because involutional changes will by definition increase with age [11].

We found the involutional ectropion $56.7 \%$ (42 patients) was of more frequently occurred disease with more involved in males with $36.45 \%$ (27 patients) than females $20.25 \%$ (15 patients). Damasceno et al [12] found involutionalectropion 68.8\% (503) in males and 31.2\% (228) in females. Miletic et al [1] found involutional $42.2 \%$, paralytic $30.8 \%, 25.0 \%$ cicatricial where as Pascali et al [9] found involutional $45.4 \%$, paralytic $30.3 \%$, cicatricial $18.2 \%$ and we have paralytic in $18.9 \%$, cicatricial $22.95 \%$ which is almost similar to their findings. All of our 14 paralytic cases were of facial nerve palsy causes were - Idiopathic in 6(8.1\%), traumatic in $4(5.4 \%)$, Post cranial tumor surgery in $2(2.7 \%)$, post ear infection in $2(2.7 \%)$ where as the study by Kwon et al [13] found idiopathic in 3 , traumatic in 3, post tumor surgery in 14 and infectious in 2 cases in total of 22 paralytic ectropionwhere as Chang et al [5] found Acoustic neuromas, Moebius syndrome and parotid gland adenocarcinoma as main cause of paralytic ectropion.

In our study the most common clinical feature was ocular discomfort or foreign body sensation (93.15\%) followed by epiphora (89.10\%) where as Marzouket al [10] found persistent tearing was the most common feature followed by unacceptable cosmesis.

Surgical treatment is the best way for correction of ectropion which is based on correct identification of the underlying etiopathogenic factors. Though there are various surgical procedure done (table 2\&3), we have found LTS + MS was most frequently used to correct ectropion followed by LTS alone. Kamet al [3] and Fradinho et al [14] suggest that the LTS alone is effective in improving symptoms, cosmetic appearance and anatomy. And those corrected with LTS + MS had also very good result considering the heterogeneity in other measures of ectropion. Though Kamet al [3] considered this combination for those whose lid position could not be adequately corrected in the lateral pinch and twist test which result was also comparable to LTS alone. Nowinski et al [15] also reported Medial spindle procedure is extremely useful for medial ectropion and as an adjunct to a lateral tarsal strip procedure if horizontal eyelid laxity or canthal malposition is also present. Lee Hwaet al [16] also reported the successful use of LTS + MS to resolve lower lid laxity and punctalectropion. This procedure also showed promising result in our cases.

We did scar release with FTSG from post auricular area to cor- rect the cicatricial ectropion which resulted very good outcome, is also comparable to Sharma et al, [17] and the study from Duke Eye center from 2000 to 2010 [18] stated that FTSG from the post auricular region is a simpler technique requiring lesser instrumentation and gives good results in restoring the lid function and cosmesis in case of post burn cicatricial ectropion. The surgical management of cicatricial ectropion depends on the situation after release of the scar traction in the lower lid area. Frequently, the resulting defect is surprisingly large after scar release. Depending on the underlying problem, the degree of ectropion and the quality of the surrounding tissue, there are different surgical methods to choose [19, 20]. A case study by Baek et al [4] also reported LTS with combination of lateral canthopexy to correct cicatricialectropion with out lateral lid malposition and in another case of cicatricial ectropion with lateral lid malposition corrected by lateral canthopexy and FTSG. Mileticet al [1] reported the surgical procedures for cicatricialectropion were Z-Plasty, local flaps, FTSG and in combinations with lateral canthal sling procedure where as he treated paralytic ectropion with medial wedge excision, medial canthoplasty and combined procedures. Chang et al [5], Kwon et al [13] and Bergeron et al [21] suggested treatment for paralytic ectropion with LTS and lateral tarsorrhaphy whenever needed to treat sever exposure keratopathy. We also used Lazy-T procedure for correction of medial ectropion as suggested by Smith Byron [22] and Mcveighet al [23] also reported 9\% of cases for correction of medial ectropion. We also did 3-Snip punctoplasty in 14 cases where the lower punctum was severely stenosed.

Our study revealed both anatomical and functional success in $83.78 \%$ with single or combined procedures which is similar to Mileticet al [1] study of $80 \%$ with single and $20 \%$ with combined procedures, Pascali et al [9] had success of $75 \%-90 \%$, Chang et al [5] had $93 \%$ success for both.

This study showed the most common complication was undercorrection in $13.50 \%$ were all paralytic ectropion, Liebau et al [19] had $18.9 \%$ overall under correction, Dryden et al [20] showed $21 \%$ under correction with involutional ectropion and $55 \%$ of under correction in cicatricial ectropion. $8.10 \%$ ( 6.75\% paralytic, $1.35 \%$ involutional ectropion) of our cases show recurrence, Liebau et al [19] found 18.9\%, Lopez-Garcia et al [24] had recurrence of $2.3 \%$. We had conjunctivitis in 1 case postoperatively Liebauet al [19] had in 11 patients. Observing in all aspect in management of ectropion our result is also consistent with others and the outcome is very good though we have some limitations of systematic assessment of the cause for each ectropion was not made, specific type of ectropion has not been defined for selected procedure, longer duration of follow up had been better since this 
study has a follow up period of 1 year after surgery.

\section{Conclusion}

This study concluded that involutional ectropion is the most common, LTS is the most commonly used surgery to correct the ectropion. Single or combined procedures according to the involved etiopathogenic cause gives very good result of anatomic and functional success with better cosmesis and patient satisfaction.

\section{References}

[1]. Miletić D, Elabjer BK, Bosnar D, Busić M. Our approach to operative treatment of lower lid ectropion. Acta Clin Croat. 2010 Sep;49(3):283-7. Pubmed PMID: 21462817.

[2]. Piskiniene R. Eyelid malposition: lower lid entropion and ectropion. Medicina (Kaunas). 2006;42(11):881-4. Pubmed PMID: 17172788.

[3]. Kam KY, Cole CJ, Bunce C, Watson MP, Kamal D, Olver JM. The lateral tarsal strip in ectropion surgery: is it effective when performed in isolation? Eye (Lond). 2012 Jun;26(6):827-32. Pubmed PMID: 22402697.

[4]. Baek S, Chung JH, Yoon ES, Lee BI, Park SH. Algorithm for the management of ectropion through medial and lateral canthopexy. Arch Plast Surg. 2018 Nov;45(6):525-533. Pubmed PMID: 30466232.

[5]. Chang L, Olver J. A useful augmented lateral tarsal strip tarsorrhaphy for paralytic ectropion. Ophthalmology. 2006 Jan;113(1):84-91. Pubmed PMID: 16343628

[6]. Kersten RC, Kulwin DR. Paralytic ectropion of the lower eyelid. Plast Reconstr Surg. 1995 Sep;96(4):991-2. Pubmed PMID: 7652081.

[7]. Hintschich C. Correction of entropion and ectropion. Dev Ophthalmol. 2008;41:85-102. Pubmed PMID: 18453763.

[8]. Hartstein ME, Klimek DL. Eyelid malposition: update on entropion and ectropion. Comprehens Ophthalmol Update. 2001;2:107-14.

[9]. Pascali M, Corsi A, Brinci L, Corsi I, Cervelli V. The tarsal belt procedure for the correction of ectropion: description and outcome in 42 cases. $\mathrm{Br} \mathrm{J}$ Ophthalmol. 2014 Dec;98(12):1691-6. Pubmed PMID: 24993105.

[10]. Marzouk MA, Shouman AA, Elzakzouk ES, Elnaggar MT. Lateral Tarsal strip technique for correction of lower eyelid Ectropion. J of Am Sci. 2011;7(5).

[11]. Mitchell P, Hinchcliffe P, Wang JJ, Rochtchina E, Foran S. Prevalence and associations with ectropion in an older population: the Blue Mountains Eye Study. Clin Exp Ophthalmol. 2001 Jun;29(3):108-10. Pubmed PMID:
11446446.

[12]. Damasceno RW, Osaki MH, Dantas PE, Belfort R Jr. Involutional entropion and ectropion of the lower eyelid: prevalence and associated risk factors in the elderly population. Ophthalmic Plast Reconstr Surg. 2011 SepOct;27(5):317-20. Pubmed PMID: 21415800.

[13]. Kwon KY, Jang SY, Yoon JS. Long-Term Outcome of Combined Lateral Tarsal Strip With Temporal Permanent Tarsorrhaphy for Correction of Paralytic Ectropion Caused By Facial Nerve Palsy. J Craniofac Surg. 2015 Jul;26(5):e409-12. Pubmed PMID: 26086924.

[14]. Fradinho N, Pereira A, Rasteiro D, Sousa J, Tojo N, Martins J, et al. Lateral tarsal strip technique for lower lid ectropion and entropion. International Journal of Oral and Maxillofacial Surgery. 2013 Oct 1;42(10):1322.

[15]. Nowinski TS, Anderson RL. The medial spindle procedure for involutional medial ectropion. Archives of Ophthalmology. 1985 Nov 1;103(11):1750-3.

[16]. Lee H, Park M, Chang M, Kang DW, Lee JS, Baek S. Clinical Characteristics and Effectiveness of the Lateral Tarsal Strip and Medial Spindle Procedure. Ann Plast Surg. 2015 Oct;75(4):365-9. Pubmed PMID: 24691326.

[17]. Sharma BR, Sharma M. Severe post thermal burn cicatricial ectropion with corneal ulceration: an illustrative case. JNMA J Nepal Med Assoc. 2005 JulSep;44(159):102-5. Pubmed PMID: 16554865.

[18]. Ehrlich MS, Richard MJ, Woodward JA. Demographic characteristics of patients requiring full-thickness skin grafts for cicatricial ectropion at Duke Eye Center from 2000 to 2010. Ophthalmic Plast Reconstr Surg. 2012 NovDec;28(6):476-7. Pubmed PMID: 23138221.

[19]. Liebau J, Schulz A, Arens A, Tilkorn H, Schwipper V. Management of lower lid ectropion. Dermatol Surg. 2006 Aug;32(8):1050-6; discussion 1056-7. Pubmed PMID: 16918568.

[20]. Dryden RM, Edelstein JP. Lateral palpebral tendon repair for lower eyelid ectropion. Ophthalmic Plast Reconstr Surg. 1988;4(2):115-8. Pubmed PMID: 3154724.

[21]. Bergeron CM, Moe KS. The evaluation and treatment of lower eyelid paralysis. Facial Plast Surg. 2008 May;24(2):231-41. Pubmed PMID: 18470835.

[22]. Smith B. The "lazy-T" correction of ectropion of the lower punctum. Arch Ophthalmol. 1976 Jul;94(7):1149-50. Pubmed PMID: 779732.

[23]. Mcveigh KA, Harrison R, Ford R. Entropion and ectropion repair: a snapshot of surgical practice in the United Kingdom. Orbit. 2018 Apr;37(2):105109. Pubmed PMID: 29053043.

[24]. López-García JS, García-Lozano I, Giménez-Vallejo C, Jiménez B, Sánchez Á, de Juan IE. Modified lateral tarsal strip for involutional entropion and ectropion surgery. Graefes Arch Clin Exp Ophthalmol. 2017 Mar;255(3):619625. Pubmed PMID: 27817116. 